1 Universidade Federal da Bahia (UFBA), Instituto de Saúde Coletiva (ISC), Programa de Pósgraduação em Saúde Coletiva - Salvador (BA) Brasil.

jamillyss@hotmail.com

2 Universidade Federal da Bahia (UFBA), Instituto de Saúde Coletiva (ISC), Programa de Pósgraduação em Saúde Coletiva - Salvador (BA), Brasil.

carment@ufba.br

\section{Posicionamento do Cebes no processo de implementação do SUS na conjuntura 2003- 2014}

\author{
Positioning of the Cebes in the implementation process of the SUS in \\ the 2003-2014 context
}

Jamilli Silva Santos', Carmen Fontes Teixeira²
RESUMO O trabalho analisou o posicionamento do Centro Brasileiro de Estudos de Saúde (Cebes), enquanto sujeito coletivo, ante as decisões governamentais com relação ao Sistema Único de Saúde (SUS) na conjuntura 2003-2014, a partir de 11 documentos e 40 editoriais da revista 'Saúde em Debate'. A entidade reconhece os avanços do SUS, mas posiciona-se criticamente quanto ao financiamento e à gestão do sistema, apontando a insuficiência de recursos e a tendência à incorporação de modalidades de gestão de serviços que estimulam a privatização da gestão pública, chamando a atenção, também, para o estreitamento das bases de sustentação política da Reforma Sanitária Brasileira, por conta da relativa desmobilização e da fragilidade da articulação dos movimentos sociais.

PALAVRAS-ChaVe Política de saúde. Sistema Único de Saúde. Reforma dos serviços de saúde.

ABSTRACT The paper analyzed the positioning of the Brazilian Center for Health Studies (Cebes), as a collective subject, in view of the governmental decisions regarding the Unified Health System (SUS) in the 2003-2014 context, based on 11 documents and 40 editorials of the journal 'Saúde em Debate'. The entity recognizes the advances of the SUS, but is positioned critically regarding the financing and management of the system, pointing to the lack of resources and the tendency to incorporate management modalities that stimulate the privatization of public management. It also highlights the narrowing of the bases of political support of the Brazilian Health Reform, due to the relative demobilization and the fragility of the articulation of social movements.

KEYWORDS Health policy. Unified Health System. Health care reform. 


\section{Introdução}

O Centro Brasileiro de Estudos em Saúde (Cebes), criado em 1976, constituiu-se no espaço no qual foi formulada a proposta de 'democratização da saúde' (CEBES, 1979), base conceitual, política e estratégica do movimento da Reforma Sanitária Brasileira (RSB) (ESCOREL, 1999; PAIM, 2008). Na década de 1980, o Cebes tornou-se um dos principais articuladores do projeto de reforma da política e do sistema de saúde, sistematizado no relatório da VIII Conferência Nacional de Saúde e institucionalizado com a aprovação do Capítulo Saúde da Constituição Federal de 1988 e das Leis $\mathrm{n}^{\circ} 8.080$ e $\mathrm{n}^{\circ} 8.142$ em 1990 (FLEURY; 1994; PAIM, 2008, 2013B), base jurídica do Sistema Único de Saúde (SUS). O processo de implementação desse projeto, ao longo dos últimos 28 anos (1988-2016), tem sido pontuado por avanços e retrocessos, aproximações e distanciamentos entre o que foi proposto nos primórdios do movimento pela RSB e o que vem sendo efetivamente realizado, em função das opções políticas adotadas pelos diversos governos que se sucederam nesse período (NORONHA; LIMA; MACHADO, 2008; TEIXEIRA; SOUZA; PAIM, 2014).

Ao ampliar a revisão da literatura na base de dados bibliográfica Scientific Electronic Library Online (SciELO) em 2015 (SANTOS; TEIXEIRA, 2016), constatou-se a existência de mais de 221 artigos que abordam diversos aspectos do processo de organização e funcionamento do sistema, porém evidenciaram-se poucos estudos que analisam o processo político em saúde, especialmente o posicionamento de organizações e entidades representativas de diversos segmentos da população brasileira acerca desse processo.

Tomou-se como ponto de partida, considerando a importância de investigar a ação política de sujeitos coletivos implicados na formulação e implementação de propostas consentâneas com os princípios da RSB em vários espaços institucionais, a seguinte questão: Qual o posicionamento político do Cebes com relação às decisões do Ministério da Saúde (MS) voltadas à implementação do SUS no período 2003-2014? O objetivo geral deste trabalho, portanto, foi analisar o posicionamento do Cebes, enquanto sujeito coletivo, ante as decisões governamentais com relação ao SUS na conjuntura 2003-2014. O recorte de tal período justifica-se pelo fato de a entidade ter enfrentado uma crise que conduziu à sua refundação, em 2006, que implicou uma reestruturação interna. Além disso, essa conjuntura corresponde aos governos Lula I, Lula II e Dilma I, contexto no qual o movimento sanitário, do qual o Cebes faz parte, criou uma expectativa com relação à possibilidade de retomada dos ideais do movimento pela RSB, cabendo, portanto, analisar o posicionamento da entidade perante políticas e estratégias implementadas nesse período.

\section{O Cebes: ator social/sujeito político}

Ao considerar o objetivo definido neste estudo, foi elaborado um modelo teórico (figura 1) que situa o lugar ocupado pela entidade no conjunto de atores sociais envolvidos no processo da RSB, bem como trata de apontar possíveis temas que se constituem em áreas-problema (CPPS; OPS, 1975) do SUS que mereceram posicionamento da entidade. Em documento intitulado 'Uma Agenda Estratégica para a saúde no Brasil' (CEBES ET AL., 2010), o Cebes destacou cada uma delas, quais sejam: o financiamento da saúde, modelos de atenção à saúde, regulação do setor privado, política de gestão do trabalho, modelos de gestão pública, desenvolvimento tecnológico e inovação e controle e participação social do SUS, as quais foram então incorporadas neste estudo. 
Figura 1: Modelo teórico

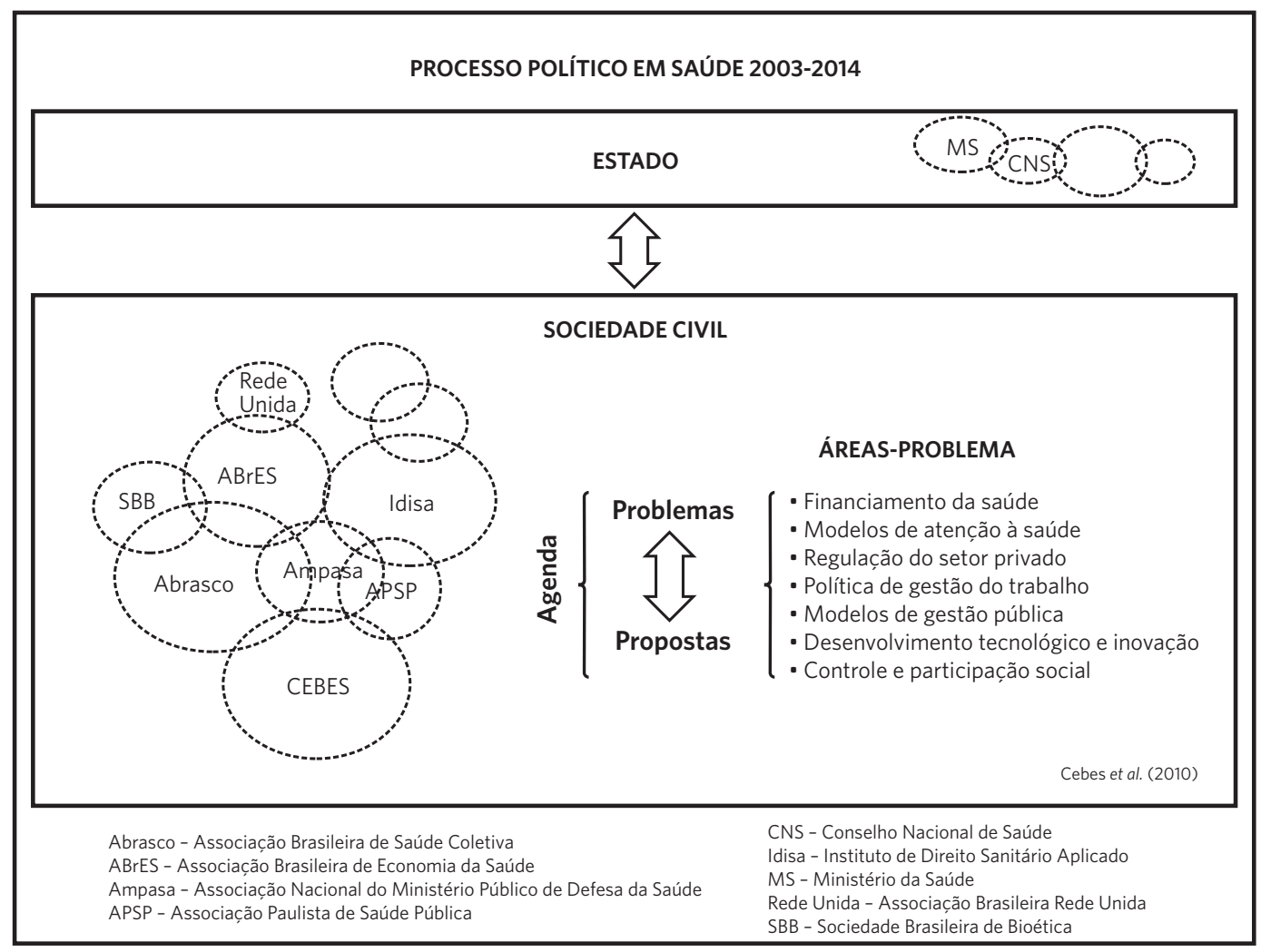

Fonte: Elaboração própria baseada em Cebes et al. (2010).

Como se pode observar no diagrama, o Cebes faz parte da sociedade civil, juntamente com outras organizações que atuam no processo político em saúde com as quais mantém relações, estabelecendo eventualmente alianças políticas e parcerias, bem como entidades cujo posicionamento distancia-se das posições por ele adotadas. Ademais, a ação política do Cebes e demais entidades da sociedade civil tem como interlocutores privilegiados as instituições estatais, notadamente o MS e o Conselho Nacional de Saúde, instância de gestão participativa do SUS, espaço de elaboração, negociação e conflito em torno das propostas apresentadas pelos diversos segmentos, inclusive aqueles que se vinculam direta ou indiretamente ao Cebes.

Esses distintos sujeitos (TESTA, 2007) e organizações podem ser entendidos como atores sociais com capacidade de introduzir temas de discussão na agenda do Estado, concebido como uma condensação de relações de força (POULANTZAS, 1981), portanto, um espaço no qual se apresentam conflitos e se estabelecem negociações visando à construção de consensos que envolvem o 'pessoal do Estado' (gestores, burocratas) e atores que representam classes sociais ou frações de classe e/ou grupos organizados da sociedade civil (partidos políticos, sindicatos, associações, entidades religiosas etc.). Nesse espaço, relacionam-se então esses múltiplos atores, envolvidos em processos de mobilização, participação e tomada de decisões que comportam conflitos, negociações e acordos com relação à Política e organização dos sistemas de saúde, por meio da utilização de estratégias institucionais, que contemplam, entre outras, a ocupação de espaços em instâncias de gestão ou na estrutura político-burocrática do MS. 


\section{Estratégia metodológica}

Estudo de caso, de caráter exploratório e descritivo, baseado na análise de documentos elaborados e divulgados pela Direção Nacional do Cebes no período 2003-2014. Foram analisados 11 documentos e 40 editoriais da revista 'Saúde em Debate' (RSD), disponibilizados no site da entidade (http://cebes.org. br/). Construiu-se uma 'linha do tempo' que incluiu a periodização dos governos que se sucederam no período estudado, os principais fatos e acontecimentos que marcaram a trajetória da política de saúde e as mudanças na composição da diretoria nacional do Cebes ao longo do período.

Com base nessa linha do tempo, foram identificados os documentos que contêm os posicionamentos do Cebes diante de questões centrais (áreas-problema) colocadas em debate no processo político em saúde nesse período. A análise de cada documento levou em conta, portanto, a identificação e extração de trechos que continham a análise das propostas governamentais e a apresentação das propostas do Cebes em cada área-problema, construindo-se assim uma matriz de análise de conteúdo (BARDIN, 2009) centrada na identificação nos 'núcleos de sentido' correspondentes a cada uma das categorias de análise indicadas no referencial teórico. A análise do conjunto do material coletado permitiu verificar até que ponto o posicionamento do Cebes aproximava-se ou distanciava-se das propostas governamentais, ou seja, se seu posicionamento foi convergente ou divergente com a direcionalidade impressa pelo MS ao processo de implementação do SUS no período estudado.

\section{Resultados e discussão}

A análise do processo de implementação do SUS foi tema recorrente nas publicações do Cebes. Motivou especificadamente quatro números da RSD: '20 anos de SUS' (CEBES,
2009A), 'Rumos do SUS: o legal e o real' (CEBES, 2011A), 'Construir o SUS como verdadeira Política Pública' (CEBES, 2011C) e 'Financiamento e gestão do SUS' (CEBES, 2014A), além de quatro documentos dedicados ao tema, quais sejam: 'O SUS pra valer' (ABRASCO ET AL., 2005), 'O lugar estratégico da gestão na conquista do SUS pra valer' (CEBES, 2005), 'Vinte anos do SUS: celebrar o conquistado, repudiar o inaceitável' (CEBES, 2009E) e 'SUS: qual o rumo?' (CEBES, 2010C), destacando-se, em todos eles, os princípios, a abrangência e profundidade do projeto do SUS, considerado "uma política de construção da democracia que visa à ampliação da esfera pública, à inclusão social e à redução das desigualdades" (ABRASCO ET AL., 2005, P. 386).

Alguns desses documentos foram produzidos pelo Cebes e demais entidades do movimento sanitário no contexto de processos eleitorais, objetivando reafirmar os princípios basilares do SUS, analisar seu processo de implementação (avanços e problemas) e, sobretudo, propor estratégias para sua efetivação, buscando assegurar o comprometimento dos candidatos e futuros gestores. Nessa perspectiva, o documento 'O SUS pra valer' (ABRASCO ET AL., 2005), lançado por ocasião das eleições presidenciais de 2006, propôs, entre outras medidas,

[...] priorizar o desenvolvimento social [...]; [...] estabelecer responsabilidades sanitárias [...] de cada ente governamental e direitos dos cidadãos usuários; realizar uma reforma administrativa [...]; e superar a insegurança e o subfinanciamento. (ABRASCO ET AL., 2005, P. 388-395)

Nas eleições presidenciais de 2010, foram lançadas pelo Cebes e por outras entidades da RSB duas Agendas (CEBES ET AL., 2010; 2011) mantendo esse compromisso. A primeira, intitulada 'Uma Agenda Estratégica para a saúde no Brasil' (CEBES ET AL., 2010), foi apresentada no período de transição do então eleito governo da presidente Dilma. Posteriormente, uma segunda versão do documento foi elaborada, 'Para fazer o SUS avançar' (CEBES ET AL., 2011), 
também endereçada à gestão nacional da política de saúde.

Por ocasião dos 20 anos do SUS, o Cebes celebrou e analisou as conquistas e dificuldades enfrentadas desde a Constituição Federal de 1988, destacando que

[...] o SUS mudou de forma radical a atenção à saúde no Brasil. É [...] uma das políticas sociais mais abrangentes e distributivas da história nacional, ao tornar o acesso à saúde universal e incluir milhões de brasileiros na condição de usuários de saúde [...]. (CEBES, 2009E, P. 185).

Além da celebração, também aponta problemas, chamando a atenção para que "[...] a saúde tem sido negligenciada em prol de uma política econômica restritiva e de acordos políticos particularistas. [...]" (CEBES, 2009E, P. 186). Diante disso, registra sua "[...] indignação com a permanência de um conjunto de problemas que atinge de forma cruel a população e ameaça os princípios conquistados" (CEBES, 2009E, P. 186).

A seguir, são apresentados tais posicionamentos levando em conta os diversos componentes do sistema apontados no modelo teórico (figura 1), os quais constituem eixos estruturais do sistema de saúde brasileiro, apresentados nas Agendas Estratégicas para Saúde no Brasil (CEBES ET AL., 2010; 2011).

a) O 'financiamento da saúde' ocupou posição de destaque entre os temas abordados pelo Cebes, sendo objeto de análise crítica e propostas alternativas às medidas governamentais. A entidade defendeu

[...] a aplicação de 10\% do PIB no setor da saúde, sendo cerca de $75 \%$ de recursos públicos [...], buscar a aprovação [...] da Emenda Constitucional (EC) 29 e [...] o fim da Desvinculação de Recursos da União [...]. (CEBES ET AL., 2010, P. 4).

Ainda, previu também
[...] rever a concessão dos subsídios públicos [...] de dedução no Imposto de Renda de Pessoa Física e Imposto de Renda de Pessoa Jurídica (IRPF e IRPJ) e o [...] pleno ressarcimento ao SUS pelas empresas de planos e seguros de saúde [...]. (CEBES ET AL., 2011, P. 5).

Ao longo do período estudado, diversas foram as críticas feitas pelo Cebes às medidas adotadas pelos governos, as quais dificultavam a efetivação do direito universal à saúde. Desse modo, a entidade denunciou "[...] que o governo federal incorporou gastos com saneamento básico e ações que deveriam ser financiadas pelo Fundo de Combate à Pobreza" (CEBES, 2003, P. 91). Também apontou que "[...] o descumprimento da EC-29 [...] mostra que muitos gestores parecem desconsiderar ser sua responsabilidade o cumprimento do dispositivo [...]" o qual garante que "Saúde é direito de todos e um dever do Estado" (CEBES, 2004, P. 89); demonstrando a “[...] marcante e contínua retração federal do financiamento do sistema público de saúde" (CEBES, 2009B, P. 193). Por efeito de medidas adotadas desde os anos 1990 pela área econômica dos governos federais, determinantes do subfinanciamento do SUS (CEBES, 2009B), as quais, segundo o Cebes, têm "[...] permitido a expansão do setor privado em áreas estritamente públicas e sendo permissivo com práticas clientelistas e patrimonialistas" (CEBES, 2009E, P. 186).

No bojo do debate fomentado pela aprovação da EC 29 em 2011, o Cebes exigiu que fosse "[...] retomado o debate do Projeto de Lei do Senado no 121/2007 [...]" (CEBES, 2011B, P. 347), bem como defendeu a criação de

[...] uma fonte de financiamento que seja exclusiva para a saúde que deve ser destinada diretamente aos Fundos Nacional, Estaduais e Municipais de Saúde. (CEBES, 2011B, P. 347).

Esse tema retornou ao debate por ocasião do lançamento do Programa Mais Médicos, quando a entidade propôs a 
[...] redução dos incentivos fiscais aos planos e seguros privados de saúde [...] e o incremento de recursos advindos dos royalties do Pré-Sal e da Taxação de Grandes Fortunas. (CEBES, 2013C, P. 203).

Finalmente, mantendo o compromisso com a defesa do financiamento adequado para a Saúde, por ocasião de novo processo eleitoral de 2014, a entidade

[...] conclama toda a população e os candidatos a cargos políticos nas eleições de 2014 a lutarem a favor do: aumento das despesas públicas com saúde da União para um mínimo de 10\% do orçamento federal. (CEBES, 2014A, P. 196).

b) Sobre a 'gestão do SUS', a entidade reconheceu, em seus documentos, a necessidade de promover mudanças direcionadas ao fortalecimento da capacidade de gestão pública das instituições e serviços de saúde, no sentido de se

[...] avançar na implantação de modelos próprios para a gestão da saúde, que assegurem a efetividade e a qualidade dos serviços, preservando o seu caráter público [...]. (CEBES ET AL., 2010, P. 4).

Propõe, assim,

[...] valorizar o critério de qualidade técnica [...] e adotar mecanismos de responsabilização de gestores, profissionais e técnicos quanto ao desempenho dos serviços de saúde. (CEBES ET AL., 2010, P. 4).

Enfatizando a necessidade de superar os problemas estruturais da administração pública brasileira, a exemplo do patrimonialismo e clientelismo (PAIM; TEIXEIRA, 2007), O Cebes destacou

[...] a importância de que a saúde não seja moeda de negociação política na composição dos governos, e [...] a necessidade de qualificação e compromisso como pré-requisito para os gestores. (CEBES, 2012A, P. 506).

Defendeu ainda a

[...] redução do número de cargos de confiança àqueles estritamente relacionados com a condução estratégica da política de saúde dos governos eleitos, reservando o preenchimento daqueles referentes aos níveis operacionais para servidores de carreira. (CEBES ET AL., 2011, P. 5-6).

Assim, enfatizou, nos editoriais da RSD, a importância da qualificação das equipes gestoras do SUS, criticando o fato da escolha dos gestores, na prática, não ser pautada pela qualificação e compromisso, mas sim pela negociação política em "[...] nome da governabilidade [...]”, considerando que essa “[...] característica da política do Estado brasileiro tem sido um dos entraves para o avanço do SUS" (CEBES, 2012A, P. 506). Além da qualificação dos gestores, a entidade destacou a importância da qualificação do nível municipal e a importância da articulação interfederativa, pois, em sua compreensão,

[...] essa visão solidária entre municípios, estados e governo federal é fundamental para a realização do SUS, mas ainda está por ser construída, não só no setor saúde, mas em toda a sociedade brasileira, marcada pela lógica capitalista e pela supremacia do individualismo sobre o coletivo. (CEBES, 2012A, P. 506).

Mais recentemente, a entidade posicionou-se criticamente com relação ao crescimento da gestão privada de serviços públicos de saúde, a partir de meados da década de 1990, com a implantação das Organizações da Sociedade Civil de Interesse Público (Oscip) e Organizações Sociais (OS), que vêm se tornando progressivamente responsáveis pela gestão de hospitais, centros de saúde, Unidades de Pronto Atendimento e Unidades de Saúde da Família. Por ocasião do debate em torno das eleições presidenciais de 2014, o Cebes expôs sua posição sobre o tema: 
[...] conclama a população brasileira e os candidatos [...] a repudiar [...] a contratação de entidades privadas para a gestão de serviços públicos de saúde, responsáveis pela introdução da lógica privada em detrimento dos interesses públicos [...]. (CEBES, 2014B, P. 195-196).

Apontou que essas entidades

[...] vêm contribuindo para a introdução, nas unidades públicas de saúde que gerenciam, de um conjunto de técnicas e valores típicos do mercado privado, de benefício duvidoso para o serviço público. (CEBES, 2014B, P. 195-196).

c) Quanto ao 'modelo de atenção à saúde', o Cebes destacou em suas Agendas Estratégicas a importância de

[...] fortalecer e expandir as estratégias de promoção da integralidade e da universalidade da atenção à saúde por meio da configuração de redes de atenção organizadas regionalmente em consonância com a situação de saúde. (CEBES ET AL., 2010, P. 5).

Além disso, sugeriu a

[...] ampliação, com padronização da qualidade, da oferta de atenção primária e criação de centros de coordenação regionais, [...] tornando a atenção primária ordenadora da rede de serviços [...]. (CEBES ET AL., 2011, P. 3-4).

Nesse sentido, em editorial no qual o Cebes analisou as repercussões de Alma-Ata por ocasião do aniversário de 30 anos da declaração, a entidade avaliou que sua

[...] essência [...] foi perdida, pois os resultados sanitários nunca foram tão desiguais no mundo, assim como nunca foi tão precário e injusto o acesso à saúde. (CEBES, 2008, P. 3).

Especificamente quanto à realidade brasileira, a entidade considerou que ainda não era consensual o lugar da Atenção Primária à Saúde (APS) no SUS, uma vez que eram distintas as abordagens acerca do papel estratégico que tal modelo assistencial poderia ocupar no processo de reorientação do sistema. Nesse sentido, problematizou as distintas concepções acerca da APS e apontou a possibilidade de esta contribuir para a mudança do 'modelo assistencial',

[...] desde que sejam superadas a superposição de redes de assistência, [...] as desigualdades no acesso e na utilização dos serviços, a pouca valorização e formação inadequada dos profissionais, a focalização e seletividade de ofertas do pronto-atendimento mínimo. (CEBES, 2008, P. 3).

Destacou ainda que, apesar das mais de duas décadas do SUS, ainda persistia um sistema de saúde que localizava o hospital no centro da atenção à saúde, demonstrando a dificuldade de apreensão da atenção primária como ordenadora do processo do cuidado diante da

[...] cultura hegemônica que sempre localizou o hospital no centro da atenção à saúde, ocasionando a persistente dificuldade de compreender o sentido real da atenção primária. (CEBES, 2012B, P. 318).

Outrossim, o Centro retomou um debate mais amplo acerca da determinação social da saúde e defendeu a formulação de políticas públicas mais amplas que privilegiassem a promoção da justiça social, ultrapassado os limites da reorganização do sistema de saúde, pois

[...] o escopo da discussão sobre determinação social da saúde tem que ser amplo, ou seja, não pode se limitar ao marco disciplinar da epidemiologia, devendo abranger uma ampla gama de questões sobre as relações entre saúde, sociedade, economia, democracia e políticas públicas. (CEBES, 2009C, P. 341-342). 
d) Diante da complexidade da 'gestão do trabalho' no SUS o Cebes defendeu a valorização do trabalhador da saúde e a melhoria das suas condições de trabalho e remuneração,

[...] eliminando a precarização, adotando parâmetros nacionais de cargos, carreiras e vencimentos para os trabalhadores da saúde e assegurando o co-financiamento das políticas de gestão do trabalho pelas três esferas de governo. (CEBES ET AL., 2010, P. 4-5).

e) A 'participação social' foi, sem dúvida, o tema mais frequentemente abordado pelo Cebes em suas publicações, seja como tema central de números da Revista em que foram abordadas as conferências de saúde e a participação social em saúde nos 20 anos do SUS (CEBES, 2010A), seja como tema secundário desenvolvido ao longo das demais publicações da entidade. Nas Agendas Estratégicas, a entidade destacou a importância de

[...] valorizar os movimentos sociais, acatando as deliberações políticas dos fóruns legítimos de participação como as Conferências e Conselhos de Saúde. (CEBES ET AL., 2010, P. 5).

Ademais, defendeu o

[...] fortalecimento do Controle Social, ampliando a representação, a representatividade, a capacidade de aglutinação de interesses e a formulação de uma agenda pautada pelas necessidades de saúde desde 2011. (CEBES ET AL., 2011, P. 6).

O Centro atribuiu tal importância ao tema porque considerava que “[...] a participação e o controle social estão entre as maiores inovações do projeto da Reforma Sanitária” (CEBES, 2006, P. 141). Além disso, a entidade destacou sua origem e compromisso com os movimentos sociais, pois,

[...] o Cebes nasceu com os movimentos sociais e populares e continua a dialogar com a sociedade e suas demandas de forma a transformar estruturas e viabilizar o projeto de equidade para a sociedade brasileira. (CEBES, 2013B, P. 550).

Em várias de suas publicações, o Centro reconheceu que as instâncias institucionais de participação social legitimadas formalmente, Conselhos e Conferências de Saúde, conferem ao setor a mais sólida estrutura de participação social entre as políticas sociais no País. Além delas, destacou também o crescimento de instâncias de participação social de representação plural no Brasil, como associações de defesas de direitos, representação de interesses específicos, sindicatos e organizações não governamentais (CEBES, 2006). Para mais, também fez críticas à ação dos movimentos sociais, ao sinalizar que “[...] no fundo, a mediocridade do debate e sua curta visão só se tornam possíveis porque os movimentos sociais estão paralisados e silenciosos" (CEBES, 2010B, P. 606). Tais problemas decorriam, segundo o Cebes, da ausência de um processo permanente de mobilização popular que resultasse na manutenção e ampliação das bases dos movimentos sociais e partidos, assim “[...] a debilidade da participação e do controle social está estreitamente vinculada à ausência de política dos movimentos sociais e dos partidos atuais" (CEBES, 2010B, P. 606). Também, destaca a inserção de muitas das lideranças desses movimentos em cargos e funções da administração pública, o que os fez "[...] distanciar ainda mais da possibilidade de uma atuação crítica, básica para o aprofundamento de sua ação política" (CEBES, 2010B, P. 606).

Nesse contexto, a entidade comprometeu-se, em várias publicações, com a retomada do debate crítico, amplo e politizado e com a “[...] formação de sujeitos instituintes, ou seja, com capacidade crítica e com voz altiva no campo da saúde" (CEBES, 2010b, p. 606), o que revelou sua preocupação com a retomada, ampliação e articulação de 
movimentos sociais que dessem sustentação política ao processo de Reforma Sanitária.

f) As propostas da entidade acerca do 'desenvolvimento tecnológico e inovação' versavam de modo geral para a integração entre as áreas de saúde, ciência, tecnologia e indústria em prol da garantia de produção nacional de insumos necessários ao funcionamento do SUS (CEBES ET AL., 2010). Nesse sentido, apareceu em um editorial da RSD a menção ao tema, como parte do debate sobre financiamento do SUS, destacando-se que sua insuficiência prejudicava a efetivação do sistema inclusive pela limitação da produção de conhecimentos e tecnologias (CEBES, 2012B).

g) Sobre a 'regulação do setor privado', o Cebes destacou, em suas Agendas Estratégicas, a necessidade de revisão dos estímulos/benefícios até então oferecidos ao setor privado, reafirmando a necessidade de

[...] garantir a capacidade de intervenção da Agência Nacional de Saúde Suplementar (ANS), orientada pelo interesse público, e [...] eliminar os subsídios públicos aos planos e seguros privados de saúde [...]. (CEBES ET AL., 2010, P. 4).

Assim, criticou o progressivo favorecimento ao setor privado ao longo do processo de implementação do SUS e, além do mais, defendeu a reversão desse favorecimento em prol do interesse público, pois

[...] é preciso [...] considerar o aumento da governabilidade do Estado sobre o setor privado de saúde, para além do que vem sendo realizado pela ANS, a partir das bases [...] da Constituição, de forma a tornar o Sistema de Saúde realmente ÚNICO. (CEBES, 2013A, P. 5).

Diante disso, como fez a cada publicação, a entidade conclamou os cebianos e a sociedade civil à mobilização, como pode ser evidenciado no trecho a seguir:

[...] é hora de refazer o pacto político que permitiu sua criação e os avanços alcançados e viabilizar o aprofundamento dessa política solidária, única solução para a construção de uma sociedade democrática com coesão social. (CEBES, 2009D, P. 5).

De modo geral, ao longo de diversas publicações, a entidade defendeu a importância do SUS enquanto uma política de Estado que garanta à população brasileira acesso à saúde universal, humanizada e de qualidade, correspondendo, portanto, à institucionalização parcial dos princípios da RSB (CEBES, 2012B). Analisou seu processo de implementação desde sua criação, destacando que apesar dos problemas, o SUS sobreviveu e se consolidou como um sistema público universal (CEBES, 2011B). Fez também críticas, demonstrando, muitas vezes, indignação com a permanência de problemas que atingem a população ameaçando, os princípios conquistados (CEBES, 2009E) e também indicou possíveis caminhos para a superação desses problemas, enfatizando sempre a mobilização dos seus associados, leitores, população e movimentos sociais em geral.

De fato, a mudança na gestão governamental ao nível federal em 2003 trouxe a expectativa da possibilidade de reorientação da política de saúde, no sentido da priorização de determinadas estratégias que implicassem o fortalecimento da gestão pública do sistema e a reversão do modelo de atenção. Vários autores apontam, em concordância com a visão do Cebes, que a mudança das forças políticas que assumiram o governo federal aumentou as expectativas com relação às políticas sociais, sobretudo a saúde, no sentido de sua reaproximação ao projeto constitucional. Esperava-se, então, o rompimento com as políticas neoliberais até então vigentes e a ampliação e fortalecimento da presença do Estado na economia de modo a propiciar às bases financeiras e institucionais a retomada e consolidação das políticas voltadas à garantia dos direitos SOciais (CARVALHO, 2013; COSTA, 2013; MENICUCCI, 2011).

Diversos estudos constatam que não 
ocorreram grandes mudanças contrariando essas expectativas. O Governo Lula manteve a mesma linha do Governo Fernando Henrique Cardoso na política econômica e na gestão das políticas sociais, compondo a "dialética do menos pior" (TEIXEIRA; PAIM, 2005, P. 282). No caso da saúde, considerando-a em seu âmbito setorial, não se verificaram "mudanças ou ações de maior envergadura" embora o País tenha se tornado "um pouco mais saudável pela via das políticas econômicas e sociais" (MENICUCCI, 2011, P. 531). Assim, apesar da retórica dos dirigentes enfatizar o interesse em priorizar a saúde, verificou-se uma "prática pífia" (CARVALHO, 2013, P. 18). Desse modo, o que foi feito não "desestabilizara o núcleo da agenda liberal”, que, pelo contrário, "avançava e ameaçava o direito universal a saúde" (COSTA, 2013, P. 244). Assim, o projeto político histórico da RSB estava sendo abandonado pelos dirigentes que assumiam a gestão da política de saúde no período pós-constituinte (PAIM, 2008).

Quanto ao posicionamento adotado pela entidade perante a política oficial conduzida especificamente pelo MS (TESTA, 2007), as publicações analisadas ilustram claramente o compromisso assumido/perseguido por ela com o ideário da RSB. Nesse sentido, é importante constatar que o Cebes formulou e divulgou um conjunto de posições críticas sobre os diversos aspectos que envolvem a efetivação desse projeto, seja em âmbito setorial relativo à implementação do SUS, seja em seu sentido mais amplo direcionado à crítica e reorientação do modelo econômico de desenvolvimento, bem como o fortalecimento das políticas sociais e a radicalização da democracia, inclusive na área de saúde.

Entre os posicionamentos adotados com relação ao processo de implementação do SUS, a entidade reconheceu os avanços, porém dedicou-se a analisar as dificuldades enfrentadas priorizando: a) crítica ao processo de subfinanciamento do SUS e apresentação de propostas alternativas para garantir a sustentabilidade financeira do sistema (cumprimento do disposto na EC 29; taxação das grandes fortunas; ressarcimento dos planos privados ao SUS, por exemplo); b) crítica e posicionamento contrário às mudanças operadas no âmbito da gestão do SUS com estímulo à expansão da privatização da gestão pública (OS, OSCIP); c) crítica à relativa paralisação no processo de mobilização e articulação dos movimentos sociais em torno da garantia do direito universal à saúde.

De forma secundária e pontual, a entidade também se posicionou com relação ao processo de manutenção/mudança dos modelos de atenção em saúde, criticando a persistência do modelo hospitalocêntrico e as dificuldades enfrentadas no processo de consolidação da APS. De mais a mais, posicionou-se, em algumas ocasiões, defendendo a necessidade de avançar no processo de regulação do setor privado, criticando o progressivo favorecimento do referido setor ao longo do processo de implementação do SUS.

Ao considerar a implementação do SUS enquanto perspectiva setorial da efetivação do projeto da RSB, os documentos apresentam também uma crítica ao modelo de desenvolvimento adotado pelos governos do período, apontam-no, inclusive, como determinante dos obstáculos ao fortalecimento do processo da RSB, destacando seus efeitos, principalmente a desmobilização e desarticulação política dos movimentos sociais. Essa crítica se acentuou, inclusive, durante o primeiro Governo Dilma, diante das ações adotadas pelo Estado na área econômica e social, as quais vêm favorecendo ainda mais a 'mercantilização da saúde'. Em consonância com as análises veiculadas nas publicações do Centro, outros autores também defendem a centralidade da crítica ao atual modelo de desenvolvimento econômico e social brasileiro, que privilegia os interesses do capital financeiro e compromete a efetivação dos direitos sociais, inclusive o direito universal à saúde (COSTA 2013; GADELHA; COSTA, 2012; PAIM, 2006).

O reconhecimento dos avanços e as críticas feitas pela entidade, citados anteriormente, 
convergem com as análises realizadas por outros autores que também destacam os benefícios alcançados e criticam o subfinanciamento, o favorecimento ao mercado privado de planos de saúde, a delegação de responsabilidade sobre o gerenciamento de serviços públicos a entidades privadas como importantes entraves impostos à efetivação do SUS ao longo das mais de duas décadas de sua implementação (CARVALHO, 2013; MENICUCCI, 2009; PAIM, 2013A; SANTOS, 2013; VIANA, MACHADO, 2008;).

Os resultados permitem ainda constatar que o principal interlocutor com o qual a entidade manteve relação ao longo do período estudado foi o MS/governo federal, pois suas publicações, em sua maioria, refletem o posicionamento diante das decisões adotadas por esta instância de gestão da política de saúde (TESTA, 1995), denunciando o rumo adotado em termos de direcionamento do processo de implementação do SUS e seu distanciamento da garantia do direito universal à saúde integral e de qualidade. Cabe destacar que o Cebes manteve seu posicionamento crítico, apesar de ter ocorrido, principalmente no período do segundo mandato do Presidente Lula, a ocupação de cargos do alto escalão do MS por militantes da RSB. Essa postura distanciada adotada pelo Cebes coaduna-se com as críticas à atuação do MS apontadas por alguns autores que destacam o "[...] caráter burocrático de sua organização, operando por meio de ações fragmentadas e desarticuladas, com baixa capacidade técnica normativa e de indução de políticas" (COSTA, 2013, P. 247), bem como a "[...] histórica fragmentação na condução nacional da política de saúde" (VIANA; MACHADO, 2008, P. 674), revelando, de certo modo, a autonomia da entidade e a coerência das sucessivas Direções da entidade, com os princípios que norteiam sua atuação enquanto centro de estudos dedicado à análise crítica do processo político em saúde.

Além dessa via, o Cebes também atuou no Conselho Nacional de Saúde e nas Conferências de Saúde. No primeiro, ocupou posição titular no grupo de representantes do segmento de profissionais de saúde, subsegmento composto por entidades representativas da comunidade científica da área da saúde. Nesse sentido, o Cebes envolveu-se no processo eleitoral para a composição do Conselho em 2006 e ao longo de todo o período estudado. Nas Conferências, reconhecendo sua importância enquanto espaços centrais de participação social em saúde, o Centro buscou contribuir para o desenvolvimento do processo de organização e relatoria, tendo, inclusive, participado da Comissão de Relatoria da XII Conferência Nacional de Saúde.

Posto isto, é importante registrar ainda o estabelecimento de alianças do Cebes com outras entidades da sociedade civil (TESTA, 2007). Tais alianças resultaram na elaboração de documentos conjuntos nos quais são reiteradas as posições dessas entidades com relação ao processo de implementação do SUS e a construção de projetos políticos que apontem para o aprofundamento da democracia e a reorientação das políticas econômicas e sociais. As entidades signatárias dos documentos analisados foram: Abrasco, ABrES, Ampasa, APSP, Conselho Federal de Medicina (CFM), Conselho Nacional de Secretarias Municipais de Saúde (Conasems), Rede Unida e Sociedade Brasileira de Medicina de Família e Comunidade (SBMFC). Há que se destacar a relação estreita com a Abrasco, enfatizada pelo próprio Cebes em seu processo de crise/ refundação e nas publicações conjuntas de ambas. A proximidade de ideais do Cebes e da Abrasco fica evidente nos documentos 'Carta em defesa da saúde do povo brasileiro' e 'Saúde, justiça e inclusão social', nos quais as entidades reconsideram e reafirmam as diretrizes da RSB e os princípios do SUS. Aliadas às demais entidades citadas, Cebes e Abrasco mantêm a defesa do SUS no documento 'O SUS pra valer', chamando ainda a população à reflexão acerca do modelo de democracia que se deseja; e no documento 'Agenda Estratégica para a Saúde no Brasil' 
o conjunto de entidades propõe cinco diretrizes para orientar a política de saúde, configurando, assim, um arco de alianças estratégicas no processo da RSB.

\section{Conclusões}

Pelo exposto, pode-se constatar que o Cebes se constituiu como um sujeito político coletivo, um ator social (TESTA, 1995) que por sua atuação política no período analisado, posicionou-se criticamente com relação ao encaminhamento dado à política governamental em saúde, defendendo sistematicamente os princípios e valores que fundamentam o projeto da RSB. Nessa perspectiva, segundo a concepção elaborada por Mário Testa, apresentada no quadro teórico, o posicionamento político do Cebes no período 2003-2014 fez parte da guerra de posições caracterizada pelo enfretamento entre um projeto mercantilista, hegemônico (PAIM, 2008), e o projeto da RSB, que gerou ao longo do período várias decisões governamentais que caracterizam o projeto racionalizador (PAIM, 2008).

Pode-se afirmar, portanto, que este trabalho evidenciou a multiplicidade de temas e de formas de atuação do Cebes no período, os quais se articulam em torno de um eixo central que é a defesa do direito à saúde como direito de cidadania e do processo de implementação da RSB e do SUS.

\section{Referências}

ASSOCIAÇÃO BRASILEIRA DE SAÚDE COLETIVA (ABRASCO) et al. O SUS pra valer: universal, humanizado e de qualidade. Saúde em Debate, Rio de Janeiro, v. 30, n. 71, p. 385-396, set./dez. 2005.

BARDIN, L. Análise de Conteúdo. Lisboa: Edições 70, LDA, 2009.

CARVALHO, G. A saúde pública no Brasil: estudos avançados, São Paulo, v. 27, n. 78, 2013. Disponível em: $<$ http://www.scielo.br/pdf/ea/v27n78/02.pdf >. Acesso em: 19 fev. 2016.

CENTRO BRASILEIRO DE ESTUDOS DE SAÚDE (CEBES). O controle social e o projeto da Reforma Sanitária [editorial]. Saúde em Debate, Rio de Janeiro, v. 30, n. 73/74, p. 141-142, maio/dez. 2006.

\footnotetext{
Direito à Saúde: 25 anos [editorial]. Saúde deba-

te, Rio de Janeiro, v. 37, n. 96, p. 4- 5, jan./mar. 2013 a.

O direito à saúde é um direito humano inadiável [editorial]. Saúde em Debate, Rio de Janeiro, v. 34, n. 84, p. 4-7, jan./mar. 2010a.
}

. Editorial. Saúde em Debate, Rio de Janeiro, v. 27, n. 64, p. 91-92, maio/ago. 2003.

Editorial. Saúde em Debate, Rio de Janeiro, v. 28,

n. 67 , p. 89 , maio/ago., 2004

Editorial. Saúde em Debate, Rio de Janeiro, v. 32, n. 78/79/80, p. 3, jan./dez. 2008.

Editorial. Saúde em Debate, Rio de Janeiro, v. 33, n. 81, p. 3-5, jan./abr. 2009a. 
Editorial. Saúde em Debate Rio de Janeiro, v. 33, n. 82 , p. 193-194, maio/ago. 2009b.

Editorial. Saúde em Debate, Rio de Janeiro, v. 33, n. 83 , p. 341-342, set./dez. 2009c.

Editorial. Saúde em Debate, Rio de Janeiro, v. 35 n. 89 , p. 184-185, abr./jun. 2011a.

Editorial. Saúde em Debate, Rio de Janeiro, v. 35, n. 90 , p. $346-348$, jul./set. 2011 b.

Editorial. Saúde em Debate, Rio de Janeiro, v. 35, n. 91, p. 502-503, out./dez. 2011c.

Editorial. Saúde em Debate, Rio de Janeiro, v. 38, n. 100, jan./mar. 2014 a.

Em defesa do direito universal à saúde: saúde é direito e não negócio [editorial]. Saúde em Debate, Rio de Janeiro, v. 38, n. 101, p. 194-196, abr./jun. 2014b.

A equidade como política [editorial]. Saúde em

Debate, Rio de Janeiro, v. 37, n. 99, p. 548-550, out./dez. $2013 b$.

A gestão municipal e a garantia do direito à saúde [editorial]. Saúde em Debate, Rio de Janeiro, v. 36, n. 95, p. 506-508, out./dez. 2012 b.

. Lições brasileiras na busca do Direito Universal à Saúde [editorial]. Saúde em Debate, Rio de Janeiro, v. 36, n. 94 , p. 317-318, jun./set. 2012 a.

O lugar estratégico da gestão na conquista do SUS pra valer. Saúde em Debate, Rio de Janeiro, v. 30, n. 71, p. 382-384, set./dez. 2005.

Partidos, governo e os equívocos sobre o SUS [editorial]. Saúde em Debate, Rio de Janeiro, v. 33, n. 81, p. 3-5, jan./abr. 2009 d.

A questão democrática na área da saúde. 1979.

Disponível em: <http://cebes.org.br/site/wp-content/ uploads/2015/10/Cebes_Saúde-e-Democracia.pdf>. Acesso em: 4 out. 2015.
Saúde e democracia, hoje [editorial]. Saúde em Debate, Rio de Janeiro. v. 34, n. 87, p. 604-606, out./dez. $2010 b$.

SUS: qual o rumo? 2010c. Disponível em: <http://cebes.org.br/site/wp-content/uploads/2014/03/SUS-Qual-o-rumo_3.pdf>. Acesso: 28 out. 2015 .

O SUS precisa de Mais Médicos e de Muito Mais! [editorial]. Saúde em Debate, Rio de Janeiro, v. 37, n. 97 , p. 200-203, abr./jun. 2013 c.

. Vinte anos do SUS: celebrar o conquistado, repudiar o inaceitável. Saúde em Debate, Rio de Janeiro, v. 33 , n. 81 , p. $185-188$, jan./abr. 2009e.

\section{CENTRO BRASILEIRO DE ESTUDOS DE SAÚDE}

(CEBES) et al. Uma agenda estratégica para a saúde no Brasil. 2010. Disponível em: <http://www.cebes.org.br/ media/File/Agenda\%20Estrategica\%20para\%20a\%20 Saude.pdf $>$. Acesso em: 19 set. 2014.

CENTRO BRASILEIRO DE ESTUDOS DE SAÚDE (CEBES) et al. Agenda Estratégica para a Saúde no Brasil. 2011. Disponível em: <http://www.saudeigualparatodos.org.br./pdf/Agenda_Saude_para_Todos.pdf>. Acesso em: 21 set. 2014.

COSTA, A. M. Saúde e desenvolvimento. In: SADER, E. (Org.). 10 anos de governos pós-neoliberais no Brasil: Lula e Dilma. São Paulo: Boitempo; Rio de Janeiro: Flacso Brasil 2013. p. 239-252.

\section{CENTRO PANAMERICANO DE PLANIFICACIÓN} DE LA SALUD (CPPS); ORGANIZACIÓN PANAMERICANA DE LA SALUD (OPS). Formulación de Políticas de Salud: Oficina Sanitaria Panamericana, Oficina Regional de la Organización Mundial de la Salud. Santiago: OPS, jul. 1975.

ESCOREL, S. Reviravolta na saúde: origem e articulação do movimento sanitário. Rio de Janeiro: Fiocruz, 1999.

FLEURY, S. Estado sem cidadãos: Seguridade Social na 
América Latina. Rio de Janeiro: Fiocruz, 1994.

GADELHA, C. A. G.; COSTA, L. S. Saúde e desenvolvimento no Brasil: avanços e desafios. Revista de Saúde Pública, São Paulo, v. 46, n. supl., p. 13-20, 2012.

MENICUCCI, T. M. G. A Política de Saúde no Governo Lula. Saúde Soc. São Paulo, v. 20, n. 2, p. 522-532, 2011.

SUS, 20 anos: balanço e perspectivas. Cadernos de Saúde Pública, Rio de Janeiro, v. 25, n. 7, p. 1620-1625, jul. 2009.

NORONHA, J. C.; LIMA, L. D.; MACHADO, C. V. O Sistema Único de Saúde - SUS. In: GIOVANELLA, L. et al. (Org.). Políticas e sistema de saúde no Brasil. Rio de Janeiro: Fiocruz, 2008. p. 435-472.

PAIM, J. S. Eqüidade e reforma em sistemas de serviços de saúde: o caso do SUS. Saude soc., São Paulo, v. 15, n. 2, p. 34-46, 2006.

Reforma Sanitária Brasileira: contribuição para a compreensão e crítica. Salvador: Edufba; Rio de Janeiro: Fiocruz; 2008.

Reforma Sanitária Brasileira: eppur sinuove.

Cadernos de Saúde Pública, Rio de Janeiro, v. 29, n. 10, p. 1927-1953, 2013a.

. A Constituição Cidadã e os 25 anos do Sistema Único de Saúde. Cadernos de Saúde Pública, v, 29, n.10, p. 1927-1953, 2013b.

PAIM, J. S.; TEIXEIRA, C. F. Configuração institucional e gestão do Sistema Único de Saúde: problemas e desafios. Ciência \&્t Saúde Coletiva, Rio de Janeiro, v. 12, supl. p. 1819-1829, nov. 2007.
POULANTZAS, N. O Estado, o poder e o socialismo. Rio de Janeiro: Edições Graal, 1981.

SANTOS, J. S.; TEIXEIRA, C. F. Política de saúde no Brasil: produção científica 1988-2014. Saúde em Debate, Rio de Janeiro, v. 40, n. 108, p. 219-230, jan./mar. 2016.

SANTOS, N. R. SUS, política pública de Estado: seu desenvolvimento instituído e instituinte e a busca de saídas. Ciência \&t Saúde Coletiva, Rio de Janeiro, v.18, n. 1, p. 273-280, 2013.

TEIXEIRA, C. F.; SOUZA, L. E.; PAIM, J. S. Sistema Único de Saúde, a difícil construção de um sistema universal na sociedade brasileira, In: ALMEIDA FILHO, N.; PAIM, J. S. (Org.). Saúde Coletiva: teoria e prática. Rio de Janeiro: Medbook, 2014, p. 121-37.

TEIXEIRA, C. F.; PAIM, J. S. A política de saúde no governo Lula e a dialética do menos pior. Saúde em Debate, Rio de Janeiro, v. 29, n. 71, p. 268-283, set./dez. 2005.

TESTA, M. Decidir en Salud: ¿Quén?, ¿Cómo? Y ¿Porqué? Salud Colectiva. Buenos Aires, v. 3, n. 3, p. 247-257, 2007

Pensamento estratégico e lógica de programação: o caso da saúde. São Paulo: Hucitec; Rio de Janeiro: Abrasco, 1995.

VIANA, A. L. D.; MACHADO, C. V. Proteção social em saúde: um balanço dos 20 anos do SUS. Physis Revista de Saúde Coletiva, Rio de Janeiro, Rio de Janeiro, v. 18, n. 4, p. 645-684, 2008.

Recebido para publicação em abril de 2017

Versão final em julho de 2017

Conflito de interesses: inexistente

Suporte financeiro: não houve 